\title{
A test of size-scaling and relative-size hypotheses for the moon illusion
}

\author{
GORDON M. REDDING \\ Illinois State University, Normal, Illinois
}

\begin{abstract}
In two experiments participants reproduced the size of the moon in pictorial scenes under two conditions: when the scene element was normally oriented, producing a depth gradient like a floor, or when the scene element was inverted, producing a depth gradient like a ceiling. Target moons were located near to or far from the scene element. Consistent with size constancy scaling, the illusion reversed when the "floor" of a pictorial scene was inverted to represent a "ceiling." Relative size contrast predicted a reduction or increase in the illusion with no change in direction. The relation between pictorial and natural moon illusions is discussed.
\end{abstract}

The demonstration by Coren and Aks (Aks \& Coren, 1988; Coren, 1989; Coren \& Aks, 1990) of a reliable moon illusion in pictures permits examination of the moon illusion under controlled conditions to a degree not previously possible in natural settings. In addition to methodological advantage, the demonstration of the moon illusion in pictures has important theoretical implications (Coren, 1989; Coren \& Aks, 1990). The use of two-dimensional pictorial arrays largely removes the contribution of structural processes associated with optical and neural processes (e.g., accommodation, convergence, angle of regard, and vestibular interactions) that are normally present in natural three-dimensional scenes (e.g., Enright, 1989; McCready, 1986; Roscoe, 1989). The remaining illusion after structural contributions have been removed may be attributed to cognitive strategies in the processing of visual information (Coren, 1989; Coren \& Girgus, 1978). The greater control afforded by the pictorial moon illusion may, then, enable manipulations that can test among the various cognitive explanations that have been offered for the illusion. Two general classes of cognitive theories can be identified.

Inferential theories assume that the illusion arises from processes that normally operate to "infer" perceived size from distance information and retinal image size. For instance, Kaufman and Rock (1962a, 1962b, 1989; see also Kaufman \& Kaufman, 2000; Rock \& Kaufman, 1962; cf. Gilinsky, 1980, 1989) have suggested that such size scaling contributes to the illusion (see also Gregory, 1963,

G.M.R. expresses appreciation to Stan Coren and Deborah Aks for making their pictorial scenes available for these experiments. G.M.R. also thanks Dale Dickson for his critique of the first experiment. Acknowledgement is due to Ronald Benner, John Krupa, and James Rivera for assistance in data collection. A preliminary report of the first experiment was presented at the meeting of the Midwestern Psychological Association, Chicago, May 1996. Correspondence should be addressed to G. M. Redding, Illinois State University, Department of Psychology, Campus Box 4620, Normal, IL 61790-4620(e-mail: gredding@ @ilstu.edu).
1965, 1967; Gregory \& Harris, 1975). The horizon moon is perceived as larger than the elevated moon because distance cues available at the horizon position produce a "registered" distance for the moon that is greater than that for the elevated moon. The relative absence of depth cues for the elevated moon is assumed to produce a default value for registered distance that places the elevated moon closer to the observer (Da Silva, 1989; Gogel, 1969; Gogel \& Da Silva, 1987; Gogel \& Mertz, 1989). Because retinal image size is the same for both moons, the "unconscious inference" is that the farther horizon moon is larger.

In support of such size-scaling explanations, Coren and Aks (1990) found that illusion magnitude increased with increasing depth-cue salience of the depicted scene in which the moon appeared. Moreover, as predicted by size scaling, the increase in illusion magnitude could be attributed to increased perceived size of the horizon moon that appeared proximal to the scene element providing the depth cues (see also Gogel, 1965, 1969, 1977; Gogel \& Mertz, 1989). Perceived size of the elevated moon that was remote from the scene elements was largely unaffected by the depth-cue salience of the scenes. This differential effect of pictorial scene depth-cue salience on perceived size of horizon and elevated moons has been successfully replicated several times (Dickson, 1993; Redding \& Dickson, 1994). ${ }^{1}$

On the other hand, contextual theories assume that the illusion arises from processes that normally enable spatial comparisons of an object with its surrounding "context" of objects in the visual field (Redding, Winson, \& Temple, 1993). For instance, Restle (1970, 1971; Restle \& Merryman, 1968; see also Baird, Wagner, \& Fuld, 1990; cf. Gilinsky, 1980, 1989) suggested that relative (angular) size contributes to the illusion (see also Sedgwick, 1986). The horizon moon is perceived as larger because the average of adjacent contextual extents, or adaptation level (Helson, 1964), is smaller than that for the moon in elevated positions. For example, the large space 
between horizon and elevated moon contributes to a high adaptation level of contextual extent for the elevated moon. The elevated and horizon moons are then contrasted away from different adaptation levels.

Coren (1992) reported an experiment that provides a possible test of the sufficiency of such relative-size explanations. Observers judged the size of horizon and elevated moons in pictorial scenes that were either upright or inverted. Inversion does not change the relative-size context in which the moon appears and, if this were the only process contributing to the illusion, it should be undiminished. However, the illusion was reduced by about $58.2 \%$ from about $5.2 \%$ for upright scenes to $2.2 \%$ for inverted scenes. Because the salience of depth cues is likely to be diminished by scene inversion (e.g., Kennedy, 1974; Pirenne, 1970; Washburn, 1899), Coren's (1992) results are consistent with inferential explanations of the moon illusion. ${ }^{2}$ Again, this effect of scene inversion has been successfully replicated (Dickson, 1993; Redding \& Dickson, 1994). ${ }^{3}$

Although these studies of depth-cue salience and scene inversion are consistent with a size-scaling contribution to the moon illusion, they do not provide a definitive test between the size-scaling and relative-size hypotheses for two reasons. First, it is possible to argue that the increasing detail of scenes required to increase depth-cue salience inevitably produces a correlated decrease in average size of contextual elements, and that effects of depth-cue salience might actually have arisen from relative size contrast. Second, scene inversion is a weak test of the relative-size hypothesis because support for the hypothesis could come only from acceptance of the null hypothesis. Failure to find an effect of a manipulation can, of course, arise for many reasons. ${ }^{4}$

The present experiments were designed to provide a stronger test by creating situations where different, directional predictions could be made for the two hypotheses. Only the depth-inducing part of the scene (the scene element) was inverted, creating scenes similar to a textured floor and ceiling (Epstein, 1966). Thus, the direction of the difference in depicted distance for moons near to and remote from the scene was reversed. The logic of prediction is illustrated in Figure 1 for upright or inverted texture gradients and a moon position near the gradient or removed from the gradient.

The size-scaling hypothesis predicts a reversed illusion because inverting the gradient represents a "ceiling" that signals a closer distance for the near moon, in contrast to the "floor" of the upright gradient, which signals a farther distance for the near moon. The far moon is removed from the gradient, and the relative absence of depth cues should produce the same default value for registered distance and same perceived size for both upright and inverted gradients.

The relative-size hypothesis predicts reduced magnitude of the usual illusion because inverting the gradient places larger elements of the gradient near the low moon, thereby increasing the adaptation level. The illusion should not reverse, however, because the gradient elements never exceed the size of the depicted moon. Adaptation level for and perceived size of the high moon should be largely unchanged because the large gap between moon and gradient remains constant for both upright and inverted gradients.

\section{EXPERIMENT 1}

\section{Method}

Participants. The 30 participants were undergraduate students enrolled in psychology courses at Illinois State University. The participants received extra credit in their course for participation. All participants were treated in accordance with guidelines published by the American Psychological Association (1992).

Stimuli. The experimental scenes illustrated in Figure 2 were produced using the schematic texture gradient (Coren \& Aks, 1990), normally oriented or inverted by reflection but maintaining the same placement on the page, with depicted moons (20-mm diameter) either near to or far from the gradient. The maximal horizontal and vertical extent of the scene element was 20.0 and $8.5 \mathrm{~cm}$, respectively. The scene element was centered with approximately $8 \mathrm{~mm}$ between the edge of the scene and the left/right sides of the page $(21.6 \times 27.9 \mathrm{~cm}$, plain white printer paper $)$. For both upright and inverted conditions, the maximal lower extent of the scene element was approximately $4 \mathrm{~mm}$ from the bottom of the page.

The centers of the two moon positions were separated by $14.5 \mathrm{~cm}$ and were on the vertical midline of the page for both upright and inverted scenes. For the upright scene the moon was centered on points $15 \mathrm{~mm}$ (near position) or $150 \mathrm{~mm}$ (far position) from the scene horizon. For the inverted scenes the moon was centered on points $15 \mathrm{~mm}$ (near position) or $150 \mathrm{~mm}$ (far position) from the maximal vertical extent of the scene. With scene inversion the size of elements in the scene proximal to the depicted moon changed from about $1 \times 3 \mathrm{~mm}$ to $6 \times 2 \mathrm{~mm}$.

A plain horizon line with a depicted moon in an intermediate position served as a practice stimulus. For both upright and inverted conditions, the distance from the top of the page to the line was $175 \mathrm{~mm}$ and the separation between depicted moon center and the line was $85 \mathrm{~mm}$. As for experimental stimuli, the depicted moon was centered on the vertical midline of the page.

The response line was $85 \mathrm{~mm}$ long and $0.3 \mathrm{~mm}$ wide, stopped at the left end by a $10-\mathrm{mm}$ vertical line. This line was positioned $14.1 \mathrm{~cm}$ from the top of another page $(21.6 \times 27.9 \mathrm{~cm}$, plain white printer paper), with its stopped end $4.3 \mathrm{~mm}$ to the left of the vertical midline of the page.

Procedure. As illustrated in Figure 3, stimulus pages were positioned on a vertical surface facing the seated participant at a distance of approximately $60 \mathrm{~cm}$. To equate projective size and shape (see also Coren \& Aks, 1990, Experiment 3), stimuli were positioned so that elevated moons were presented $10^{\circ}$ above eye level and low moons were presented $10^{\circ}$ below eye level. The four experimental stimuli were presented in a random order. For each stimulus, a sheet of paper containing a response line was placed on the table in front of the participant. Participants responded by placing a mark on the response line so that the distance between their mark and the stopped end of the line matched the diameter of the depicted moon. An initial trial with the horizon line and depicted moon in the intermediate position (i.e., at eye level) ensured that participants understood the task.

\section{Results and Discussion}

Measures of illusion magnitude and direction were obtained for each participant and for each gradient orientation by finding the difference in reproduced-size re- 

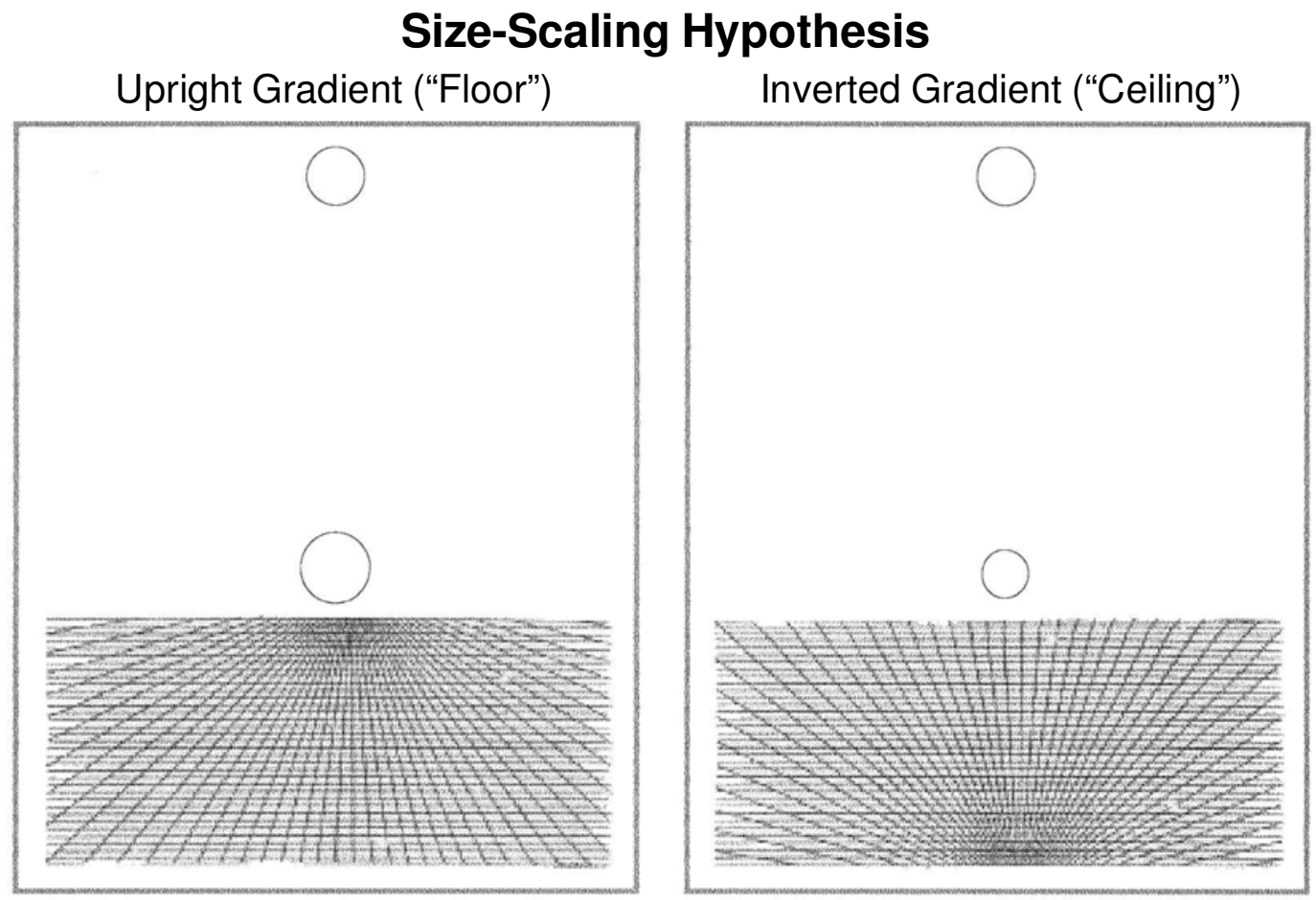

Relative-Size Hypothesis
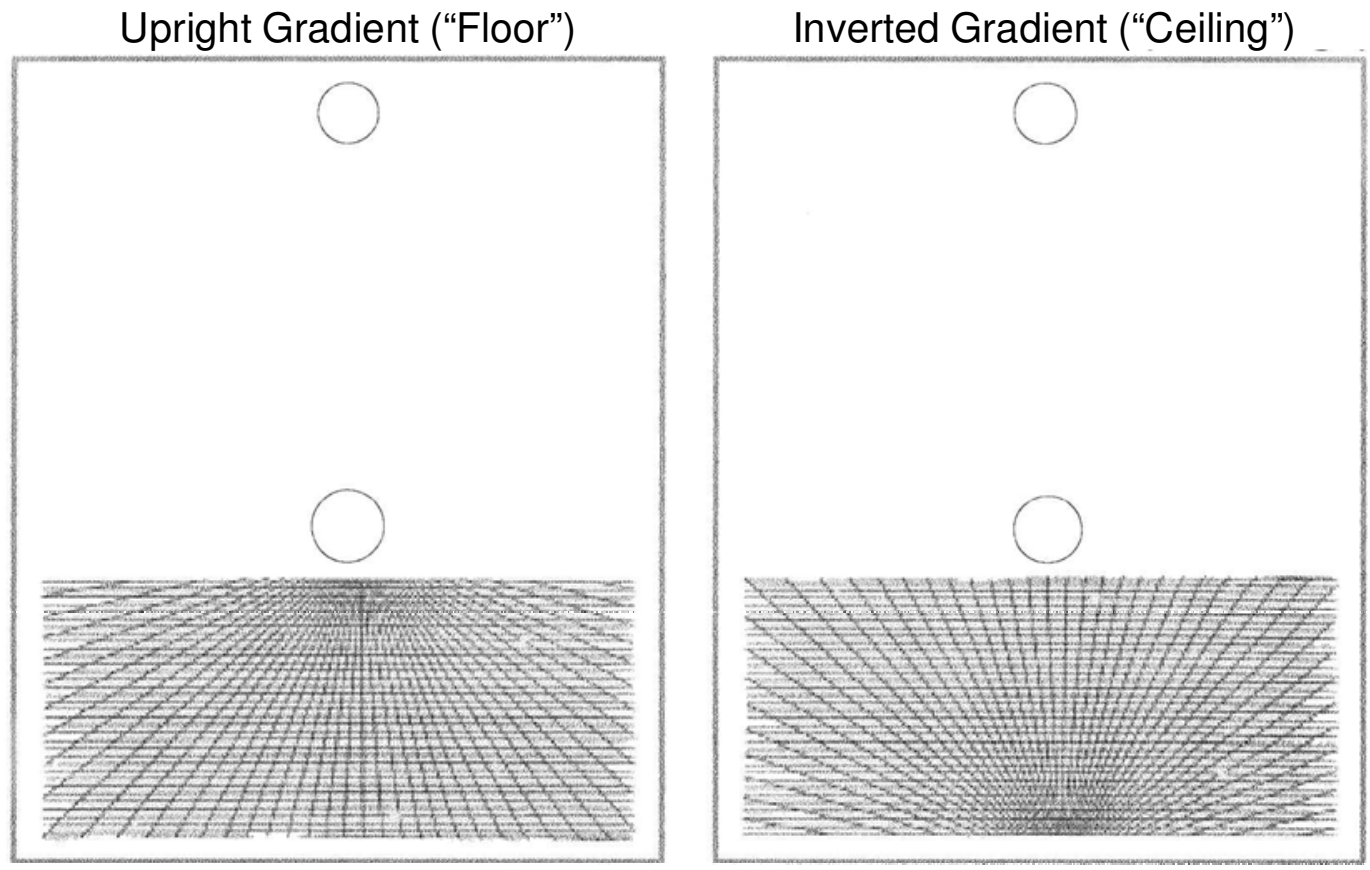

Figure 1. Predicted difference in perceived size of near and far moons for upright and inverted gradients according to the constancy-scaling and relative-size hypotheses. Drawn sizes of moons near to and far from the scene element are actually different, showing the expected direction of effect for each depicted situation.

sponses for the moon in near and far positions. A positive value indicates the usual moon illusion and a negative value indicates a reversed illusion.

Results are illustrated in Figure 4. With upright gradients, the usual illusion occurred, with the near moon judged $0.7 \mathrm{~mm}$ larger than the far moon. The illusion was reversed, however, for inverted gradients, where the near moon was judged $0.9 \mathrm{~mm}$ smaller than the far moon. Despite the high variability among participants, indicated by the $95 \%$ confidence limits in Figure 4, this 

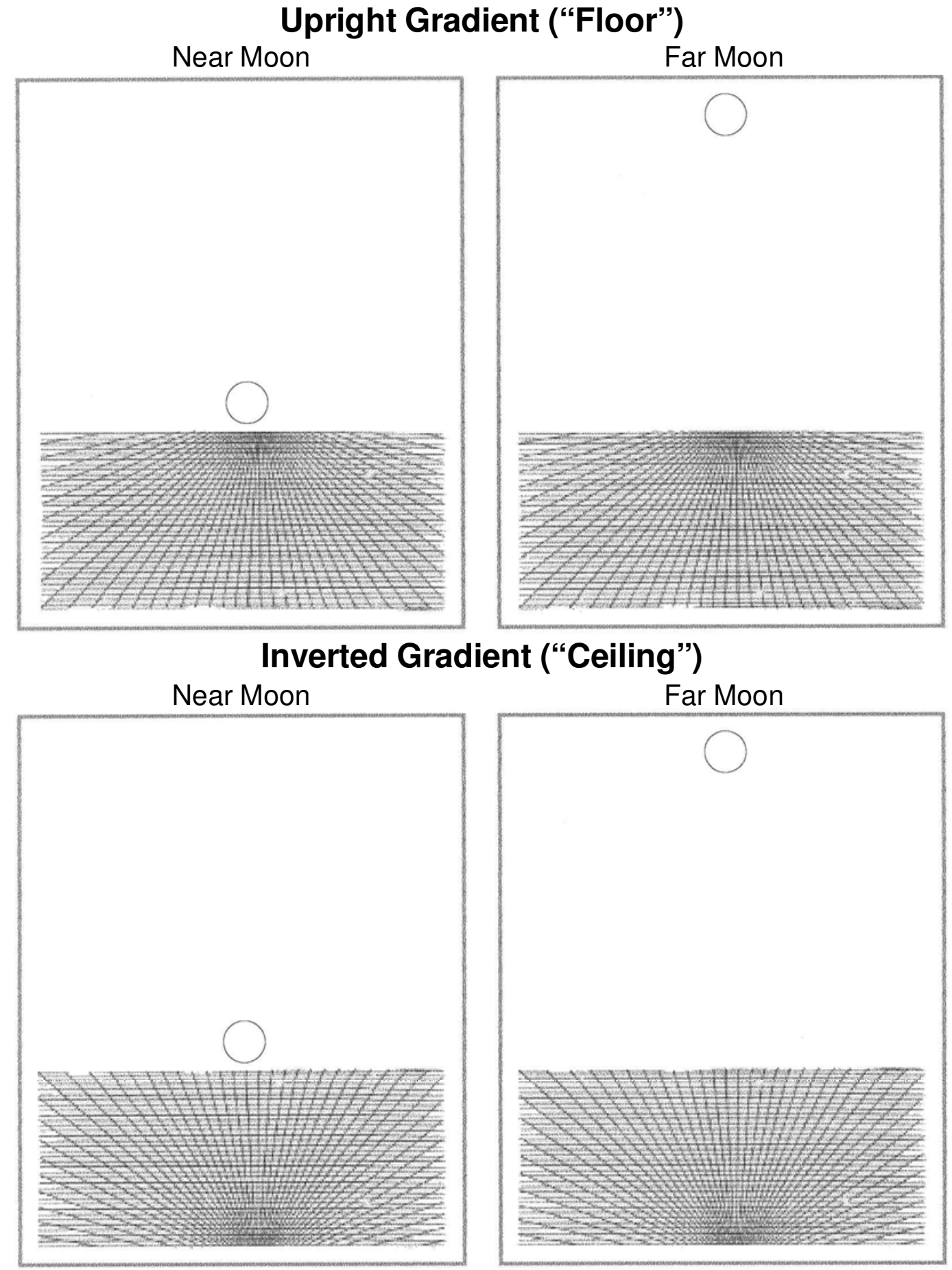

Figure 2. Illustration of the four experimental conditions of Experiment 1 defined by factorial combinations of upright or inverted texture gradient and near or far moon. The actual size of the depicted moon is the same in all four scenes.

difference in direction of the illusion was statistically reliable $[t(29)=2.76, p=.005]$. Moreover, $80 \%$ of participants showed the usual illusion for upright gradients and $77 \%$ showed a reversed illusion with inverted gradients.
Although consistent with the size-scaling prediction, the illusion was quite small in magnitude: only $3.4 \%$ for the upright scene and $4.4 \%$ for the inverted scene. In contrast, Coren and Aks (1990, Experiment 2) were able to achieve an illusion as large as $11 \%$ using higher depth- 


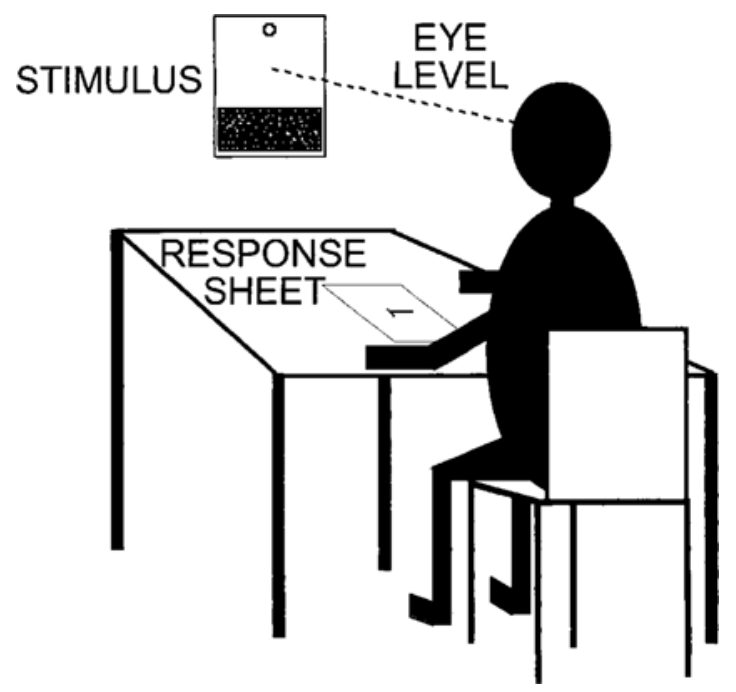

Figure 3. The relative position of stimulus, response sheet, and participant used in the present experiments is illustrated.

cue salience scenes with a measurement procedure comparable to that of the present experiment. ${ }^{5}$ The second experiment, therefore, was designed to produce a more convincingly large illusion.

\section{EXPERIMENT 2}

The schematic texture gradient used in the first experiment was third from the lowest in depth-cue salience rating out of the eight scenes used by Coren and Aks (1990). Experiment 2 employed the next to highest of Coren and Aks's scenes in rated depth-cue salience, the old European city scene, to produce a larger illusion. Predictions for scene inversion from the size-scaling hypothesis were the same as in the first experiment: a reversed illusion for the inverted scene relative to the upright scene. However, as can be seen in Figure 5, inverting the city scene moved smaller elements closer to the depicted moon, and the relative-size hypothesis might predict a larger illusion for the inverted scene than for the upright scene. For the upright scene the size of the two buildings (objects) most proximal to the depicted moon averaged about $6 \times 8 \mathrm{~mm}$, but when the scene was inverted the depicted cobblestones of the street became proximal to the depicted moon and they averaged about $4 \times 6 \mathrm{~mm}$.

\section{Method}

The method for the second experiment was the same as that of the first experiment with the following exceptions. The European city scene was used, as depicted in Figure 5. The maximal horizontal and vertical extent of the scene element was 20.2 and $13.6 \mathrm{~cm}$, respectively. The scene element was centered with approximately $8 \mathrm{~mm}$ between the edge of the scene and the left/right sides of the page $(21.6 \times 27.9 \mathrm{~cm}$, plain white printer paper). For both upright and inverted conditions, the maximal lower extent of the scene element was approximately $4 \mathrm{~mm}$ from the bottom of the page.

Three different moon sizes $(15,20$, and $25 \mathrm{~mm})$ were used. The centers of the two moon positions were separated by $7.2 \mathrm{~cm}$ and were $9.8 \mathrm{~cm}$ from the left side of the page for both upright and inverted scenes. For the upright scene the moon was centered on points $20 \mathrm{~mm}$ (near position) or $92 \mathrm{~mm}$ (far position) from the scene horizon. For the inverted scenes the moon was centered on points $20 \mathrm{~mm}$ (near position) or $92 \mathrm{~mm}$ (far position) from the maximal vertical extent of the scene. Practice scenes were the same as in the first experiment, but with three different moon sizes.

The factorial combination of scene orientation, moon position, and moon size produced 12 stimuli, presented in random order. The 40 participants were different from those of Experiment 1, but were from the same source and were treated in the same manner.

\section{Results and Discussion}

Measures of illusion magnitude and direction were obtained for each participant and for each gradient orientation by finding the difference in reproduced-size responses for each of the moon sizes in near and far positions. A positive value indicates the usual moon illusion and a negative value indicates a reversed illusion. The data were averaged over the control variable of moon size.

Results are illustrated in Figure 6. With upright scenes, the usual illusion occurred, with the near moon judged $1.9 \mathrm{~mm}$ larger than the far moon. The illusion was reversed, however, for inverted gradients, where the near moon was judged $1.1 \mathrm{~mm}$ smaller than the far moon. Thus, the higher depth-cue salience scene produced larger effects than in Experiment 1. The percentage illusion was 9.7 for the upright scenes and 5.6 for the inverted scenes. ${ }^{6}$ The lower random variability among par-

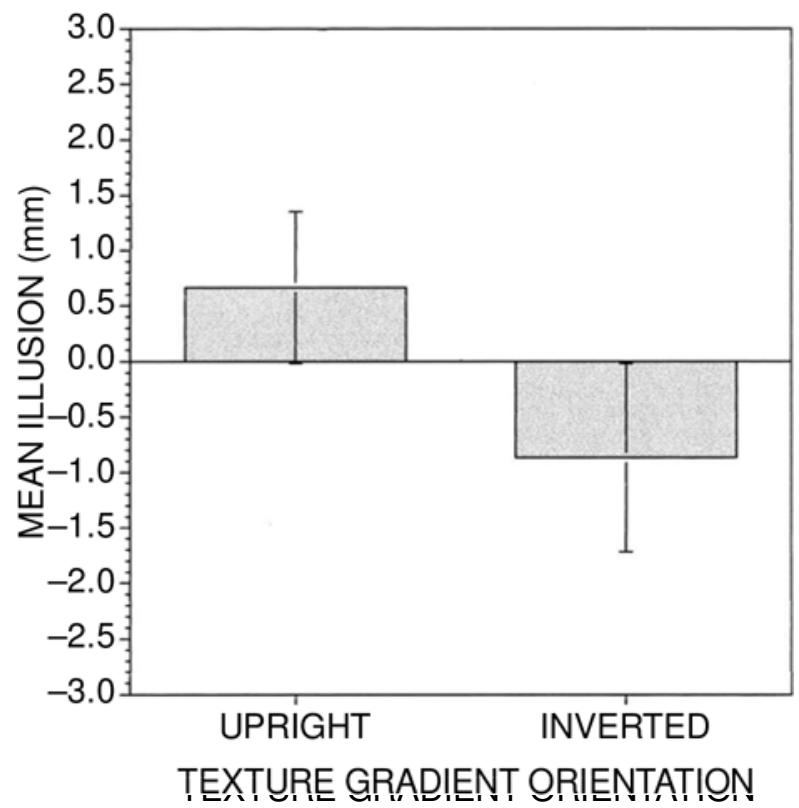

Figure 4. Average difference in reproduced size for near and far moons (i.e., mean illusion) with normally oriented and inverted texture gradients in Experiment 1. Error bars denote the 95\% confidence limits. Eighty percent of the participants receiving the upright gradient reported the illusion in the normal direction, and $77 \%$ of participants receiving the inverted gradient reported a reversed illusion. 


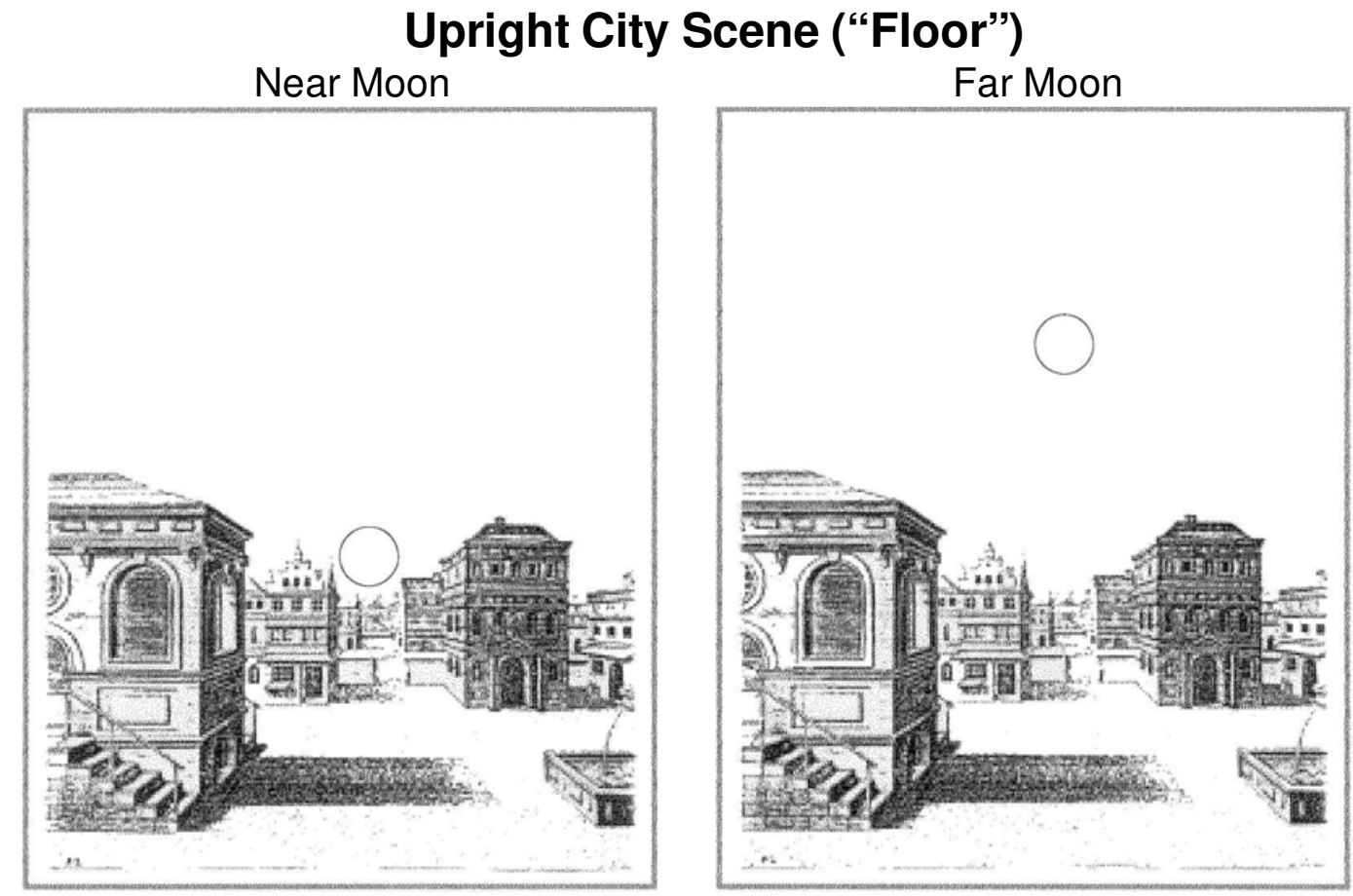

\section{Inverted City Scene ("Ceiling")}
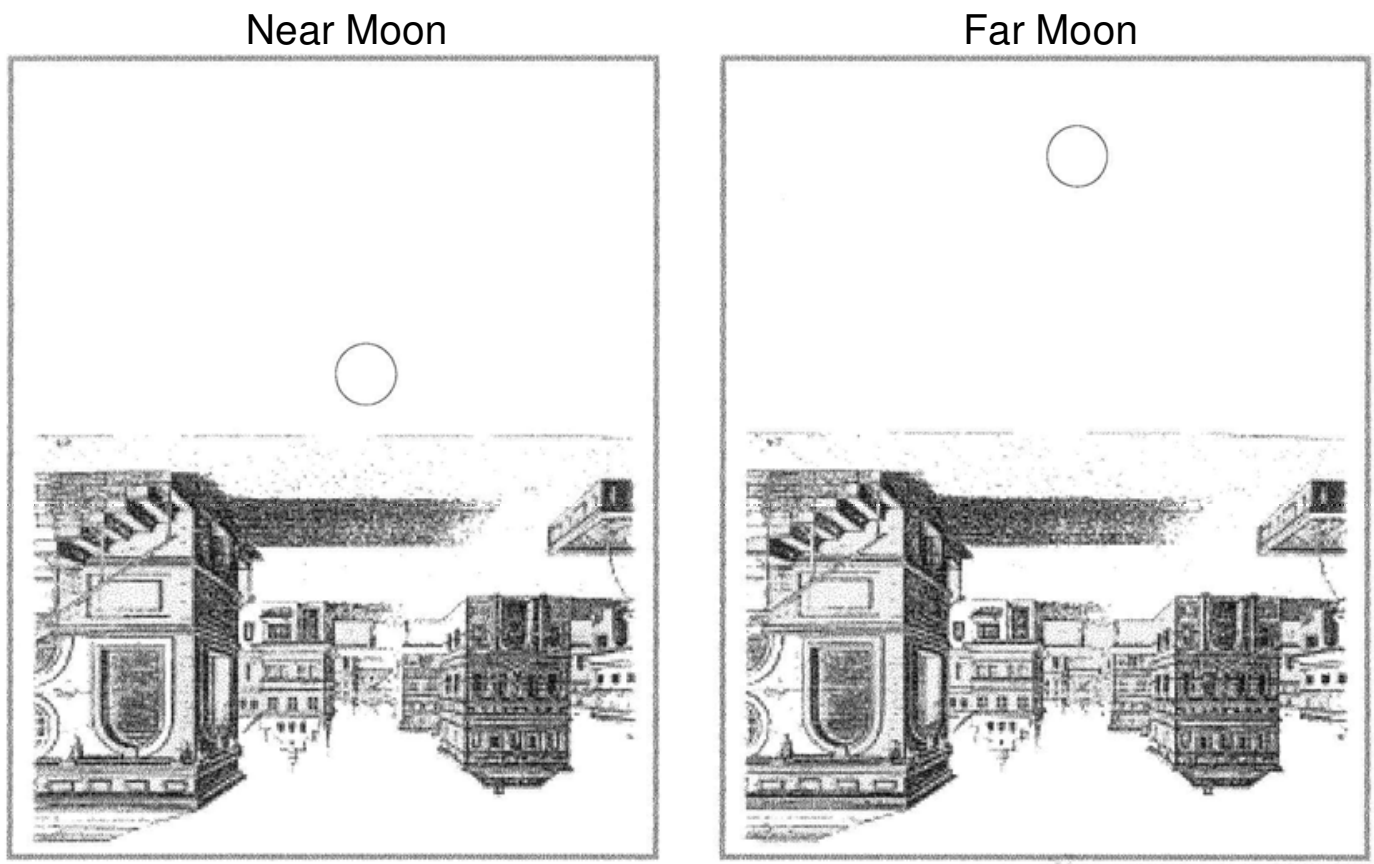

Figure 5. Illustration of the four experimental conditions of Experiment 2 defined by factorial combinations of upright or inverted city scenes and near or far moon. Only one of the three moon sizes is illustrated.

ticipants is also indicated by the $95 \%$ confidence limits in Figure 6, and this difference in direction of the illusion was statistically reliable $[t(39)=6.00, p<.001]$. Moreover, $88 \%$ of participants showed the usual illusion for upright gradients and $75 \%$ showed a reversed illusion with inverted gradients.
These results confirm those of the first experiment, conforming to prediction from the size-scaling hypothesis. As in the first experiment, the data provide no support for the relative-size hypothesis. The prediction from this hypothesis of a larger illusion with scene inversion was not confirmed. 


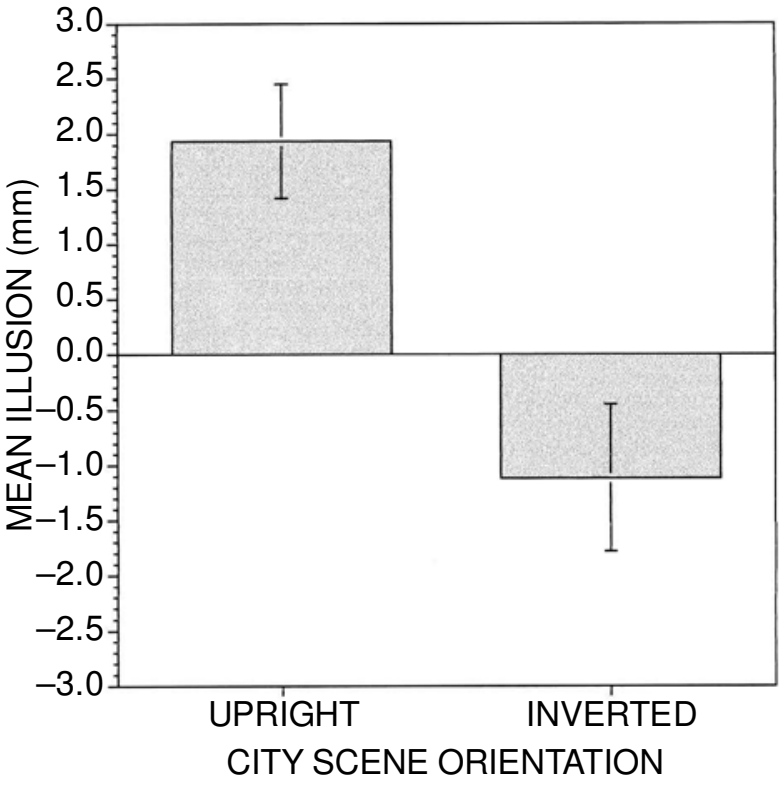

Figure 6. Average difference in reproduced size for near and far moons (i.e., mean illusion) with normally oriented and inverted city scenes in Experiment 2. Error bars denote the $95 \%$ confidence limits. Eighty-eight percent of the participants receiving the upright scene reported the illusion in the normal direction, and $75 \%$ of the participants receiving the inverted scene reported a reversed illusion.

\section{GENERAL DISCUSSION}

These data reveal no indication of a simple reduction (Experiment 1) or increase (Experiment 2) in the usual illusion with inversion of the scene element, as predicted if relative-size contrast were the only source of the illusion. On the contrary, the reversed illusion with scene element inversion strongly supports a contribution of size scaling to the moon illusion (Coren \& Aks, 1990; Kaufman \& Kaufman, 2000; Kaufman \& Rock, 1989). Thus the present results provide support for neither relative angular size (Baird et al., 1990; Restle, 1970) nor the hypothesized effects of accommodation and convergence on perceived angular size (Enright, 1989; McCready, 1986; Roscoe, 1989) because there are arguably no such differences between moons depicted in pictures. It is possible, of course, that such bases for the illusion might be operative in natural settings, but Kaufman and Rock (1989) and Kaufman and Kaufman (2000) have marshaled convincing arguments against such a possibility.

Confidence in these conclusions, however, must be qualified by how well results using pictorial stimuli can be generalized to natural settings. Coren and Aks (1990) demonstrated important similarities between the moon illusion in pictures and in natural settings. The moon illusion in pictures varied with depicted distance information (Coren \& Aks, 1990, Experiments 1-4) in much the same way that it does with distance to the visible horizon in natural settings (Rock \& Kaufman, 1962). The sizedistance paradox in natural settings, where the horizon moon appears closer than the elevated moon (Boring, 1943, 1962), also occurred in pictures (Coren \& Aks, 1990, Experiment 5). Interestingly, Coren and Aks (Experiment 6) found that the smaller judged distance of the pictured horizon moon was related to greater depicted depth in the same way that the magnitude of the pictorial moon illusion was related to greater depicted depth.

The most striking difference between pictorial and natural moon illusions is in the magnitude of the illusion. The illusion ratio ${ }^{7}$ for natural settings reported by Kaufman and Rock (1989) varied from 1.25 to 1.83. The present experiments produced illusion ratios for normally oriented scenes of only 1.04 and 1.10 for Experiments 1 and 2, respectively. Coren and Aks (1990, Experiment 2) reported a ratio of only 1.12 using a measurement procedure similar to that employed in the present experiments. But in Coren and Aks's fourth experiment, where participants drew in the moon, the illusion ratio for pictures varied from 1.19 to 1.60 , depending upon the depth cue salience of the depicted scene, with an average of 1.36 .8 Although these estimates are more in line with those obtained in natural settings, the "draw the moon" method has no counterpart in studies using natural settings, so the estimates using such methodology may not be comparable.

There are several related possible reasons why the pictorial moon illusion might be smaller than the natural moon illusion. The obvious flatness of the picture may conflict with and reduce the influence of the depicted depth (Gregory, 1963). More generally, recovery of the depicted virtual structure may be inaccurate (Kubovy, 1986; Pirenne, 1970; Rogers, 1995; Rosinski \& Farber, 1980; Sedgwick, 1980). Kaufman and Kaufman (2000) have directly attributed the small illusion in pictures to the scaling of depicted depth cues by the actual distance (binocular disparity) between the observer and the page, which is smaller than the distance between the observer and a natural scene. Thus, although other factors may influence the magnitude of the illusion, they appear to do so by affecting depicted depth, and the pictorial moon illusion does not appear to be fundamentally different from the natural moon illusion.

Although the present data clearly support a contribution from size scaling to the moon illusion, they do not necessarily establish a direct, functional relationship involving perceived size, visual angle, and perceived distance as specified by the size-distance invariance hypothesis (e.g., Epstein, Park, \& Casey, 1961; Kilpatrick \& Ittelson, 1953). The size-distance paradox (Boring, 1943; Gruber, 1954) has been widely taken as evidence contrary to the size-distance invariance hypothesis (Gillam, 1995; Rogers, 1995; Sedgwick, 1986). There seems to be some agreement that depth cues can affect both perceived size and perceived distance independently (Gillam, 1995; Kaufman \& Kaufman, 2000), but the idea that distance 
judgments may not be based on the same depth cues that are responsible for perceived size (i.e., "registered" distance; Kaufman \& Kaufman, 2000; Rock \& Kaufman, 1962) has not received general acceptance (Gillam, 1995; Rogers, 1995; Sedgwick, 1986). It may be that both size and distance scaling reflect constrained interpretation of local sensory information within the momentary perceptual representation of total visual space constructed from multiple sources of information (Gilinsky, 1980, 1989).

\section{REFERENCES}

AKs, D. J., \& Coren, S. (1988, June). The moon illusion in pictures. Paper presented at the meeting of the Canadian Psychological Association, Montreal, Canada.

American Psychological Association. (1992). Ethical principles of psychologists and code of conduct. American Psychologist, 47, 15971611.

Baird, J. C., Wagner, M., \& Fuld, K. (1990). A simple but powerful theory of the moon illusion. Journal of Experimental Psychology: Human Perception \& Performance, 16, 675-677.

Boring, E. G. (1943). The moon illusion.American Journal of Physics, 11, 55-60.

Boring, E. G. (1962). On the moon illusion. Science, 137, 902-906.

Coren, S. (1989). The many moon illusions: An integration through analysis. In M. Hershenson (Ed.), The moon illusion (pp. 351-370). Hillsdale, NJ: Erlbaum.

Coren, S. (1992). The moon illusion: A different view through the legs. Perceptual \& Motor Skills, 75, 827-831.

Coren, S., \& AKs, D. J. (1990). Moon illusion in pictures: A multimechanism approach. Journal of Experimental Psychology: Human Perception \& Performance, 16, 365-380.

Coren, S., \& Girgus, J. S. (1978). Seeing is deceiving: The psychology of visual illusions. Hillsdale, NJ: Erlbaum.

DA Silva, J. A. (1989). Gogel's laws and the simulated moon illusion in a large open field. In M. Hershenson (Ed.), The moon illusion (pp. 319-342). Hillsdale, NJ: Erlbaum.

DicKSon, D. R. (1993). The moon illusion in pictures: A test of sizeconstancy constraints. Unpublished master's thesis, Illinois State University, Normal.

ENRIGHT, J. T. (1989). The eye, the brain, and the size of the moon: Toward a unified oculomotor hypothesis. In M. Hershenson (Ed.), The moon illusion (pp. 59-122). Hillsdale, NJ: Erlbaum.

EPSTEIN, W. (1966). Perceived depth as a function of relative height under three background conditions. Journal of Experimental Psychology, 72, 335-338.

Epstein, W., Park, J., \& CASey, A. (1961). The current status of the size-distance invariance hypothesis. Psychological Bulletin, 58, 491514.

Gilinsky, A. S. (1980). The paradoxical moon illusions. Perceptual \& Motor Skills, 50, 271-283.

Gilinsky, A. S. (1989). The moon illusion in a unified theory of visual space. In M. Hershenson (Ed.), The moon illusion (pp. 167-192). Hillsdale, NJ: Erlbaum.

Gillam, B. (1995). The perception of spatial layout from static optical information. In W. Epstein \& S. Rogers (Eds.), Perception of space and motion (pp. 23-67). New York: Academic Press.

GoGEL, W. C. (1965). Equidistance tendency and its consequences. Psychological Bulletin, 64, 153-163.

Gogel, W. C. (1969). Equidistance effects in visual fields. American Journal of Psychology, 82, 342-349.

GoGel, W. C. (1977). The metric of visual space. In W. Epstein (Ed.), Stability and constancy in visual perception: Mechanisms and processes (pp. 129-182). New York: Wiley.

Gogel, W. C., \& DA Silva, J. A. (1987). A two-process theory of the response to size and distance. Perception \& Psychophysics, 41, 220-238.

Gogel, W. C., \& Mertz, D. L. (1989). The contribution of heuristic processes to the moon illusion. In M. Hershenson (Ed.), The moon illusion (pp. 235-258). Hillsdale, NJ: Erlbaum.
GREGORY, R. L. (1963). Distortion of visual space as inappropriate constancy scaling. Nature, 199, 678-680.

Gregory, R. L. (1965). Reply to Humphrey and Morgan. Nature, 206, 745-746.

Gregory, R. L. (1967). Comments on the inappropriate constancy scaling theory of the illusions and its implications. Quarterly Journal of Experimental Psychology, 19, 219-223.

Gregory, R. L., \& Harris, J. P. (1975). Illusion-destruction by appropriate scaling. Perception, 4, 203-220.

GRUBER, H. E. (1954). The relation of perceived size to perceived distance. American Journal of Psychology, 67, 411-426.

Helson, H. (1964). Adaptation level theory: An experimental and systematic approach to behavior. New York: Harper.

KaUfman, L., \& KaUfman, J. H. (2000). Explaining the moon illusion. Proceedings of the National Academy of Sciences, 97, 500-505.

Kaufman, L., \& Rock, I. (1962a). The moon illusion. Scientific American, 207, 120-130.

Kaufman, L., \& Rock, I. (1962b). The moon illusion, I. Science, 136, 953-961.

Kaufman, L., \& Rock, I. (1989). The moon illusion 30 years later. In M. Hershenson (Ed.), The moon illusion (pp. 193-234). Hillsdale, NJ: Erlbaum.

Kennedy, J. M. (1974). A psychology of picture perception. San Francisco: Jossey-Bass.

Kilpatrick, F. P., \& Ittelson, W. H. (1953). The size-distance invariance hypothesis. Psychological Review, 60, 223-231.

Kubovy, M. (1986). The psychology of perspective and Renaissance art. Cambridge: Cambridge University Press.

McCready, D. (1986). On size, distance, and visual angle perception. Perception \& Psychophysics, 37, 323-334.

Pirenne, M. H. (1970). Optics, painting, and photography. Cambridge: Cambridge University Press.

Redding, G. M., \& Dickson, D. R. (1994, May). Pictorial moon illusion as a function of depth-cue salience, scene orientation, and repeated trials. Paper presented at the meeting of the Midwestern Psychological Association, Chicago.

Redding, G. M., Winson, G. D., \& Temple, R. O. (1993). The Müller-Lyer contrast illusion: A computational approach. Perception \& Psychophysics, 54, 527-534.

Restle, F. (1970). Moon illusion explained on the basis of relative size. Science, 167, 1092-1096.

Restle, F. (1971). Visual illusions. In M. H. Appley (Ed.), Adaptation level: A symposium (pp. 55-79). New York: Academic Press.

Restle, F., \& Merryman, C. T. (1968). An adaptation-level theory of a relative size illusion. Psychonomic Science, 12, 229-230.

Rock, I., \& Kaufman, L. (1962). The moon illusion: II. Science, 136, 1023-1031.

Rogers, S. (1995). Perceiving pictorial space. In W. Epstein \& S. Rogers (Eds.), Perception of space and motion (pp. 119-163). New York: Academic Press.

Roscoe, S. N. (1989). The zoom-lens hypothesis. In M. Hershenson (Ed.), The moon illusion (pp. 31-58). Hillsdale, NJ: Erlbaum.

RosinsKI, R. R, \& FARBER, J. (1980). Compensation for viewing point in the perception of pictured space. In M. A. Hagen (Ed.), The perception of pictures: Vol. 1, Alberti's window: The projective model of pictorial information (pp. 137-176). New York: Academic Press.

Sedgwick, H. A. (1980). The geometry of spatial layout in pictorial representation. In M. A. Hagen (Ed.), The perception of pictures: Vol. 1, Alberti's window: The projective model of pictorial information (pp. 33-90). New York: Academic Press.

SEdGwICK, H. A. (1986). Space perception. In K. R. Boff, L. Kaufman, \& J. P. Thomas (Eds.), Handbook of perception and human performance: Vol. 1. Sensory processes and perception (pp. 21.1-21.57). New York: Wiley.

WASHBURn, M. (1899). The perception of distance in the inverted landscape. Mind, 3, 438-440.

\section{NOTES}

1. Rock and Kaufman (1962) also found that the illusion increased with increased apparent distance from the horizon in a natural setting. 
2. Interestingly, Rock and Kaufman (1962) found a similar effect for optical inversion of a natural scene. Although their percentage illusions were much larger for the normal orientation $(66 \%)$ and the inverted orientation (28\%), the percentage reduction $(57.6 \%)$ was nearly identical to that found by Coren (1992). Whatever the basis for the illusion, it may be that scene inversion has a constant effect.

3. Coren (1992) did not specify whether inverted scenes were produced by reflection or rotation of upright scenes. If rotation was used, lateral symmetry was not the same for inverted and upright scenes. Experiments in the author's laboratory controlled for this possible confound by using reflection to produce scene inversion.

4. It may be noted, moreover, that Restle (1970) and Baird et al (1990) attributed the reduced illusion with scene inversion (Rock \& Kaufman, 1962) to attention-induced changes in adaptation level. Sedgwick (1986) has criticized such appeals to selective attention as "making it possible to give a post hoc account for virtually any conceivable result" (pp. 21.12). In any case, such explanations are not applicable to the manipulation employed in the present experiments.
5. Percentage illusion scores were calculated relative to the actual size of the target for comparison with Coren and Aks (1990). They are somewhat larger (3.7 and 4.6) when calculated relative to the judged size of the moon remote from the scene, as is done in natural settings, where there is no definable size for the target. The $11 \%$ illusion found by Coren and Aks (Experiment 2) increases to $12.2 \%$ when calculated in this manner.

6. These percentages were 10.1 and 5.6 when calculated relative to the judged size of the moon remote from the scene.

7. Defined as the ratio of judged size of the moon near the scene horizon to the judged size of the moon remote from the scene horizon. An illusion is indicated by values greater than 1 .

8. It may be noted that these drawn-moon results have been successfully replicated several times by students in the author's laboratory class.

(Manuscript received June 13, 2001; revision accepted for publication March 29, 2002.) 